\title{
TRAJETÓRIAS DO ENCONTRO ENTRE \\ A PSICOLOGIA E O JUDICIÁRIO ${ }^{\star}$
}

\author{
Celso Campos Bivar \\ Fernanda Machado Maciel \\ Vitor Ferreira Isidro ${ }^{\star \star}$ \\ Lygia Santa Maria Ayres ${ }^{\star \star \star}$ \\ Cecília Maria Bouças Coimbra ${ }^{\star \star \star \star}$
}

Palavras-chave: Especialismo. Produção de subjetividade. Psicologia jurídica.

InTRodução E OBJEtivos: O Estatuto da Criança e do Adolescente (ECA), Lei 8.069/90, ao redefinir a política de proteção integral para a infância e a juventude brasileiras convoca novos parceiros e impulsiona novas engrenagens, visando a garantia de cidadania à população infanto-juvenil. A regulamentação do cargo de psicólogo no espaço jurídico foi uma das medidas implementadas nessa lei. O objetivo deste trabalho é propor uma análise das práticas presentes em alguns dos Juizados da Infância e Juventude do Estado do Rio de Janeiro, a partir da entrada dos profissionais aprovados no primeiro concurso público para o cargo de psicólogo do Judiciário neste estado, em 1998. Ao estudarmos as relações produzidas nestes espaços pelo atravessamento de instituições tais como Psicologia e Justiça, estamos também, colocando em análise alguns efeitos das práticas psicológicas aí presentes, bem como do especialismo Psicologia Jurídica.

Fundamentação Teórica: Utilizamos a perspectiva histórico-genealógica, proposta por Michel Foucault, pensando o percurso histórico como construtor de acontecimentos surgidos ao acaso, num jogo de forças onde algumas prática/ discursos acabam por assumir estatutos de verdade em detrimento de outras. A noção de produção de subjetividade de Félix Guattari, também atravessa nossas análises, onde os processos de subjetivação são entendidos como produção ao mesmo tempo existencial e social. Também seguindo os apontamentos da pesquisa-intervenção, entendemos nosso trabalho como um processo onde pesquisador e pesquisado se constroem ao mesmo tempo.

^ Este trabalho foi desenvolvido no Programa PIVETES (Programa de Intervenção Voltado às Engrenagens e Territórios de Exclusão Social) que se vincula ao LASP (Laboratório de Subjetividade e Política), ao Departamento de Psicologia e ao Serviço de Psicologia Aplicada da Universidade Federal Fluminense, tendo sido apresentado como Sessão Coordenada no III Congresso NorteNordeste de Psicologia, "Construindo a Psicologia Brasileira: Desafios da Ciência e Prática Psicológica”, realizado na Fundação Espaço Cultural, em João Pessoa/PB, de 27 a 31 de maio de 2003.

$\star \star$ Graduando do Curso de Psicologia - UFF; Graduanda do Curso de Psicologia - UFF e bolsista CNPq/PIBIC/UFF; Graduando do Curso de Psicologia - UFF.

$\star \star \star$ Doutoranda em Psicologia - UERJ e Técnica do SPA (Serviço de Psicologia Aplicada) - UFF.

$\star \star \star \star$ Professora Adjunta do Curso de Psicologia - UFF (Graduação, Mestrado e Pós-Graduação), Doutora pela Universidade de São Paulo e Vice-presidente do Grupo Tortura Nunca Mais - RJ. E-mail: gsi@vm.uff.br 
Metodologia: Realizamos entrevistas com 11 psicólogos que atuam nos Juizados da Infância e Juventude do Rio de Janeiro, em seus Núcleos Regionais de Comarcas (NURC). Tomamos também como material de análise as discussões propostas no Encontro de Restituição da pesquisa, que contou com a presença de alguns psicólogos entrevistados, outros profissionais da área e alunos do curso de Psicologia da UFF, que estagiam no Juizado da Infância e Juventude e Conselho Tutelar de Niterói.

Resultados e Conclusão: Ao estudarmos as relações produzidas no judiciário pelo atravessamento de instituições tais como Psicologia e Justiça, buscamos colocar em análise alguns efeitos das práticas psicológicas aí presentes. Apesar da forte influência de uma determinada "leitura psicanalítica" no cotidiano desses profissionais, da produção de certas verdades que legitimam o poder do juiz, percebemos a emergência de questionamentos aos modelos tradicionais de família, infância, adolescência, assistência, dentre outros. Da mesma forma, constatamos um movimento de desconstrução do lugar do psicólogo enquanto um especialista neutro, objetivo e apolítico. Inicia-se, assim, uma análise de suas implicações, do lugar por ele ocupado na produção de padrões de normalidade que têm servido à consolidação/naturalização da exclusão social. Destacamos a Restituição como um importante analisador que evidenciou a riqueza das experiências desses psicólogos e os vários matizes de seu trabalho, alertando o grupo de pesquisa para a força e soberba da prática da academia, que acaba por vezes sufocando ou desvalorizando falas e práticas do cotidiano. Nesse sentido, a Restituição foi uma intervenção que não se reduziu à esfera "pesquisa" ou "academia", mas serviu como um analisador de nossas mais diversas práticas. 